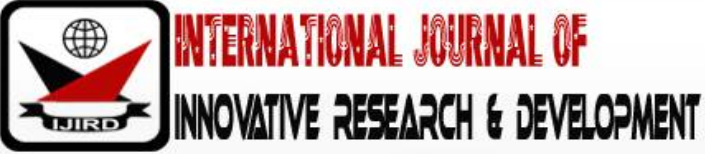

ISSN 2278-0211 (Online)

\section{Mitigating Threat to Academic Libraries: Operational Optimization for Effective Service Delivery}

\begin{tabular}{|c|}
\hline Gilbert Paul Igboechesi \\
Assistant Librarian, Department of Library, University of Jos, Plateau State, Nigeria \\
Martyns Eric Godwin \\
Assistant Librarian, Department of Library, University of Jos, Plateau State, Nigeria
\end{tabular}

\begin{abstract}
Libraries and learning have been inseparable as far as civilization is concerned. Today, the modes of learning however, are dynamic in ways that are not very familiar to us all. Developments in Information communication technology (ICT), added to the Internet era, are transforming not only the ways in which libraries work, but also those primary philosophies of the library.

This paper focuses on the mitigating threats to academic libraries, advocating for operational optimization for effective service delivery so that it can serve the 21st century user's need. In doing this, primary data was used, buttressed by other secondary sources to reveal and proffer seeming viable solutions that the academic library should consider in other to keep themselves in tune with the needed, and at the same time, fulfill the aspiration of its users. It is expected that the opinion of the researchers will go a long way in helping libraries remain the ultimate temples of knowledge to prevent the looming laxity facing the importance of library services.
\end{abstract}

Keywords: Library, academic library, Information Communication Technology (ICT), service delivery

\section{Introduction}

Libraries have existed as long as records have been kept. It first came into being with the intent to organize collections of documents. These collections consisted of archives of the earliest form of writing like the clay tablets in cuneiform script. On this, the Greek played a big role in the idea of 'book collecting' which is to be called Library later (Britannica.com).Then, there was no distinction between a record room, archive and a library Staikos, K (2007). Being dynamic in nature, it later translated to academic discipline devoted to the study of the history of diverse disciplines in life Staikos, K (2007).Today, the library has evolved that its importance in any society and academic environments cannot be over emphasized. Its traditional roles and functions have been evolving in tune with the need and demand of its users. One of the greatest advancement or paradigm shift that has dramatically impacted and made a rapid change in the academic library environment ever is Information Communication Technology (ICT). It has brought about immense pressure and limitless spheres in information accessibility that it has become an imbedded part of the library, this means that any $21^{\text {st }}$ century library that is not in tune with the numerous measures of ICT in accessing and passing across information is automatically in the phase of a moribund library. This paradigm shift requires highly skilled librarians. According to Mathews (2014): 'Evidence has convinced me that the 21st Century Library Paradigm shift is that libraries will be defined by those librarians running them and their local community more than by the profession, or any librarian associations' standards'. This translates to people who will come together and work as a team; as enablers who go the extra mile to make things work when it is actually snowballing, those who understand the advantages and disadvantages of each service rendered at the library, they offer every service with a high level of expertise to build the confidence needed at the library; Librarians who have the desire to acquire and/or have high level of information (science) technology expertise among other relevant knowledge needed. These Librarians must have a placed mission which is: 'All Users remain the defining Force in our Libraries' which is in tandem with one of the basic laws of the library as postulated by Ranganathan. Hence, Mathews (2014) opined that 'Public Libraries must agree upon a mission if we are to survive'. All hands must effectively be on deck to meet the challenge of satisfying the 'defining force'.

On this ground, one might be tempted to ask, why the academic library? Why not use the various search engines available online to get what one needs? To answer this, the premise made above is vital to what will be said eventually because, going by what is established already, it automatically means that the academic library is a sole collector, manager, preserver and disseminator of information, hence the need to transform it into a technically equipped one to serve the modern user. According to Williams (2015), academic library is not just about 'research' or information literacy... it must be seen as a place where all aspects of the Approaches to Learning are inspired in new ways'. He gave examples like the library being a place for 'Reflection, Information literacy skills, Critical thinking, Creative-thinking, Transfer skills, Affective skills, Organization skills, Collaboration and Communication' 
Academic libraries exist for the following core reasons:

- The authentication of the material and its source is valid when information emanates from the library, unlike the case of Wikipedia that a sizeable amount of library users easily use. This can be either through the digital library or the traditional / conventional library.

- It caters for all levels in any given academic environment; in learning and teaching styles, by providing the needed access to a wide range of curriculum resources like digital, print, audio and video etc. Connecting learners to power sources of information that are key to their study, research etc.,

- The Library is liberal, not restricting or positioning anyone to one style, opinion or medium of knowledge. It therefore runsan independent learning program style. And these days, it has integrated information resources and technologies for effective and smooth running. It gives its users some sense of ownership, independence and selfdetermination that leads to feeling of being empowered to take action.

- It equips the academic environment (Students and Teachers/Lecturers alike) with the necessary skills to succeed in a constantly changing technological, social and economic environment.

- The Library also comes to play in planning, implementing and evaluatinginquiry-based programs thatmay lead to the acquisition of skills to critically analyze, organize information, and create or invent problem-solving technologies, theories etc.

- Promotes the habit of reading that subsequently improve the pedigree of the users' intellect, aesthetic, cultural and emotional growth. Because it is an important source of knowledge that develops all minds, irrespective of age, academic status and gender.

Therefore, any $21^{\text {st }}$ century library that is found lacking in making sure that its users are in tune with its operations and actively using their platforms, translates to a dreadful dungeon for such library. Because going by the needs articulated already, the library makes or unmakes a society; one has to know first, before one can act! Not knowing automatically translates to Garbage in Garbage out (GIGO), where anything goes, not minding trends, norms etc., is largely a failure of access to information.

Haven $x$-rayed the underlining position of the library to the place of things in any given society,this research addresses the threats facing academic libraries, focusing on the advancement of its operations and service delivery.

\subsection{Study Objectives}

- To illuminate on the need for academic libraries

- To investigate the adequacy of the library services offered to students in the University of Jos.

- To investigate the threats to academic libraries encountered by patrons based on the provision of library services in university of Jos.

- To determine the strategies suitable for enhancing the library services offered by university of Jos to its users/patrons.

\subsubsection{Scope of the Study}

This study covers the Mitigating Threat to Academic Libraries: Operational Optimization for Effective Service Delivery in University of Jos, with focus on the traditional library system and the need to migrate.

\section{Research Methodology}

This paper is first, experimental by design, by way of primary research as most of the data was collected and collated by the researchers by way of questionnaires, interviews and observations to aid in gaining the first-hand information needed for the research. Secondly, secondary sources like databases, related books, articles, and web searches were also in hand to aid the research. These methods were adopted to give the paper a cohesive pedigree so as to launch the needed grounds to commence the research.

\subsection{Significance of the Study}

This research finding will be of benefit to the following categories of people: students, librarians/library workers, library management and indeed, the university management.

On the part of students, it will unveil a path to effective service usage or patronage of library recourses while the librarians/library officers deliver needed services, to still make them relevant and a center piece to the quest to know more. To the university and library management, it will spur them to make policies and develop programs that will stimulate the library user and encourage the library staff to brace up to the evolving challenges of effective service delivery in the library.

It is expected that this study will open up another phase of research to contribute to the existing works in the field of threat to academic libraries and operational optimization for effective service delivery.

\subsection{Population of the Study}

The research population of this study is on registered library users/patrons of university of Jos. The simple random sampling technique was adopted in order to enhance the probability of each user of the library to have equal chance of being chosen as part of the samples proportional to the size of the University of Jos library space and active patrons. This process was meticulously carried out to avoid bias in the distribution of questionnaire to respondents. 


\subsection{Sample and Sampling Techniques}

The sample of the study is made up of 70 patrons selected from the University of Jos Library, Bauchi Road Campus. A simple random sampling was used for the patrons as described above.

\subsection{Instrument for Data Collection}

The instruments are Questionnaire and interview. The instrument for data collection was divided into two sections: Collection of personal data such as institution and qualification. The second section is comprised of the proper questions for the research. The respondents were required to tick or shade the space provided. Structured interview was also conducted.

\subsubsection{Method of Data Collection}

The questionnaire was distributed using the simple random sampling among the library users. The questionnaire was administered and collected after completion by the researchers themselves. Interviews were also conducted by both researchers respectively.

\subsubsection{Method of Data Analysis}

The simple percentage method was adopted for calculation of result. The research result is presented in a tabular format and the frequencies of respondent were used to calculate the percentage of each item in all the tables from 1.0 to 2.9. The percentage for each item in the table was calculated using the formula of: $N=\frac{x}{y} \times \frac{100}{1}$

The $\mathrm{N}$ in the above formula represents simple percentage, $\mathrm{X}$ represents the number of responses, and $\mathrm{Y}$ is thetotal number of responses. This therefore means:

$\frac{\text { Number of responses }}{\text { Total number of response }} \times \frac{100}{1}$

\subsection{Data Presentation and Analysis}

The data collected was presented in tabular form and organized systematically in line with the research question and items in the questionnaires. Ninety (90) copies of the questionnaire was made available and distributed. However, only 70 copies were completed and returned to the researchers.

Tables 1 to 11 are the analysis based on the responses from the respondents of the Library users at the University of Jos.

- How often do you come to the library in a week?

\begin{tabular}{|c|c|c|c|}
\hline S/N & Items & Responses & Percentage \\
\hline A & Very High Extent (Vhe) & 12 & 17.1 \\
\hline B & High Extent (HE) & 20 & 28.7 \\
\hline C & Low Extent (LE) & 26 & 37.1 \\
\hline D & Very Low Extent (VLE) & 8 & 11.4 \\
\hline E & Indifferent & 4 & 5.7 \\
\hline
\end{tabular}

Table 1

The table above shows that $17.1 \%$ of the respondents only come to the library on a very high degree, $28.7 \%$ come on a high degree, $37.1 \%$ don't come to the library often, $11.4 \%$ scarcely come to the library, while $4.3 \%$ of are indifferent about their frequency to the library. From this analysis, it is clear that library users are more on the path of low patronage.

- Why do you come to the library?

\begin{tabular}{|c|c|c|c|}
\hline S/N & Items & Responses & Percentage \\
\hline A & Read & 22 & 31.5 \\
\hline B & Use Library Resources & 20 & 28.6 \\
\hline C & Borrow Books & 2 & 2.9 \\
\hline D & Charge devices & 13 & 18.7 \\
\hline E & Use Wi-Fi & 9 & 12.9 \\
\hline F & Relax in between lectures & 1 & 1.4 \\
\hline G & Indifferent & 0 & 0 \\
\hline
\end{tabular}

Table 2

The above table shows that $31.5 \%$ of the respondents come to the library just to read only, $28.6 \%$ come to use the library resources like the computers, consult different materials (hard and soft copies), only $2.9 \%$ come to the library to borrow books. Surprisingly, $18.7 \%$ come to the library to charge their devices like phones, laptops etc., this is because they are sure that there is always power supply in the library as a result of its usage in powering the computers for internet accessibility. $12.9 \%$ come to the library to use the Wi-Fi (connectivity) of the library to browse with their laptops, phones etc. $1.4 \%$ of the respondents use the library for relaxation after lectures or a place to just 'cool off'while waiting or expecting their next lectures. From this analysis, it is clear that majority of the library users come to the library to read their books only, not to use the library resources. While the other respondents come to use the library resources, a very 
disturbing discovery is the percentage of students that come to the library to just charge their devices only. It means that the primary reason expected from the library users is not very encouraging

- Were your needs met at the Library?

\begin{tabular}{|c|c|c|c|}
\hline S/N & Items & Responses & Percentage \\
\hline A & Very High Extent (VHE) & 9 & 12.9 \\
\hline B & High Extent (HE) & 37 & 52.9 \\
\hline C & Low Extent (LE) & 12 & 17.1 \\
\hline D & Very Low Extent (VLE) & 10 & 14.3 \\
\hline E & Indifferent & 2 & 2.8 \\
\hline
\end{tabular}

Table 3

Table 3 shows that $12.9 \%$ of the respondents affirm that their needs were highly met while 52.9 of them affirmed that it was met to a high extent. $17.1 \%$ of the respondents posited that their needs where met poorly met, $14.3 \%$ are of the opinion that theirs were very below expectations while $2.8 \%$ are indifferent about it. Therefore, an overwhelming number of the respondents are of the view that their needs where met.

The underlining aspect of the high volume of the respondents affirmation is seen in Table 2; if the reasons the respondents opted for are merged according to the needed answer in Table 2 , it will be discovered that the high percentage is not tied to the very important services of the library services, hence the reason for the high degree of affirmation.

- Have you ever borrowed books from the library using your library cards?

\begin{tabular}{|c|c|c|c|}
\hline S/N & Items & Responses & Percentage \\
\hline A & Very High Extent (VHE) & 1 & 1.4 \\
\hline B & High Extent (HE) & 5 & 7.2 \\
\hline C & Low Extent (LE) & 21 & 30 \\
\hline D & Very Low Extent (VLE) & 42 & 60 \\
\hline E & Indifferent & 1 & 1.4 \\
\hline
\end{tabular}

Table 4

The above table shows $1.4 \%$ of the respondents saying that they have actually borrowed books from the library very much, $7.2 \%$ have also borrowed but not as much as the ' $\mathrm{A}$ ' respondents, $30 \%$ posits that their borrowing capacity is below average, a large group of respondents; $60 \%$ clearly states that they far from actual borrowing of any book from the library before, while $1.4 \%$ is indifferent about the issue of book borrowing. This analysis goes to show that majority of the library users don't borrow books from the library. This further consolidates the place of the respondents on the real reason for library usage in Table 4

- Are you aware of the library's electronic databases?

\begin{tabular}{|c|c|c|c|}
\hline S/N & Items & Responses & Percentage \\
\hline A & Very High Extent (VHE) & 10 & 14.3 \\
\hline B & High Extent (HE) & 25 & 35.7 \\
\hline C & Low Extent (LE) & 12 & 17.1 \\
\hline D & Very Low Extent (VLE) & 20 & 28.6 \\
\hline E & Indifferent & 3 & 4.3 \\
\hline
\end{tabular}

Table 5

$14.3 \%$ of the respondents are highly aware of the electronic database from the above table, $35.7 \%$ say that they aware of it, $17.1 \%$ are have poor awareness on its existence, $28.6 \%$ have very poor knowledge of its existence while $4.3 \%$ are indifferent about the issue of electronic database. From the forgoing, it is clear that the library users with knowledge about electronic database are more in number, but it is not an overwhelming control as the ignorant ones are on the high side too.

- $\quad$ Have you ever used the University of Jos Online Public Access Catalogue(OPAC)?

\begin{tabular}{|c|c|c|c|}
\hline S/N & Items & Responses & Percentage \\
\hline A & Very High Extent (VHE) & 0 & 0 \\
\hline B & High Extent (HE) & 4 & 5.7 \\
\hline C & Low Extent (LE) & 19 & 27.1 \\
\hline D & Very Low Extent (VLE) & 40 & 57.1 \\
\hline E & Indifferent & 7 & 10 \\
\hline
\end{tabular}

\section{Table 6}

While there are no affirmative responses on the very strong aspect of this question, the above table shows those that have used the University of Jos OPAC as just $5.7 \%$ while $27.1 \%$ have poorly used it and a huge percentage; $57.1 \%$ have not really used. $10 \%$ are indifferent, which can also be seen as a negative to the figures gathered on this aspect. The 
analysis of this table shows that a very influencing number of the respondents (library user) don't actually access the University of Jos OPAC while making use of the library. This goes to prove that they have other sources of getting information, independent of the already provided one by the University. From the research conducted by Apuke and Iyendo, (2018) on some selected northern Nigerian universities about the search engine and internet sources mostly used by the students for their academic research and learning:

'About (52.8\%) of students had more preference for Google and Google Scholar, followed by Yahoo search (16.4\%), Bing (12.4\%) and wink (8\%), while (10.4\%) were neutral. The findings demonstrated that ADSU students (60.2 $\%)$ were heavier users of Google and Google Scholar, followed by UNIMAID (50\%) and TSU (48.2\%). Whilst TSU (24\%) students claim to use Yahoo search more than UNIMAID (16.7\%) and ADSU (8.4\%)'

In the light of the above, the most common medium for accessing needed information is Google, followed by Google scholar and then yahoo search before any other.

- How easy is it for you to find information in the University of Jos library?

\begin{tabular}{|c|c|c|c|}
\hline S/N & Items & Responses & Percentage \\
\hline A & Very Easy & 6 & 8.6 \\
\hline B & Easy & 19 & 27.1 \\
\hline C & Difficult & 33 & 47.2 \\
\hline D & Very Difficult & 7 & 10 \\
\hline E & Indifferent & 5 & 7.1 \\
\hline
\end{tabular}

Table 7

The above table shows the respondents view on the ease of getting needed information from the University of Jos Library. $8.6 \%$ are of the view that it is very easy, $27.1 \%$ posit that it is easy, $47.2 \%$ respondents said it is difficult, $10 \%$ agrees that it is very difficult while the indifferent has 7.1\%. From the above table, it is clear that the respondents' perception about access to information in the library is difficult; it is usually not what they can get in a simple or easy way.

- Are you aware of subject librarians in the University of Jos Library?

\begin{tabular}{|c|c|c|c|}
\hline S/N & Items & Responses & Percentage \\
\hline A & Very High Extent (VHE) & 10 & 14.3 \\
\hline B & High Extent (HE) & 12 & 17.1 \\
\hline C & Low Extent (LE) & 29 & 41.4 \\
\hline D & Very Low Extent (VLE) & 19 & 27.1 \\
\hline E & Indifferent & 0 & 0 \\
\hline
\end{tabular}

Table 8

The University of Jos operates the 'Subject Library Model' (Akintunde, 1999). In this model, the subject librarians head the subject libraries representing all the faculties of the institution. Therefore, the library users from each of these faculties are supposed to know and be in touch with their subject librarians help them understand and make use of the library in the expected way, especially in their respective fields of study and research. The researchers sort to know the respondents view on the subject librarians. The above table shows that $14.3 \%$ of the respondents are highly aware that there are subject librarians in the University of Jos Library, 17.1 are on the average awareness level, 41.4 have poor knowledge on that while 27.1 have very poor knowledge on that, also interpreted as not knowing of its existence.

- In relation to your course of study, do you know your subject librarian?

\begin{tabular}{|c|c|c|c|}
\hline S/N & Items & Responses & Percentage \\
\hline A & Yes & 24 & 34.3 \\
\hline B & No & 37 & 52.9 \\
\hline C & Indifferent & 9 & 12.8 \\
\hline
\end{tabular}

Table 9

The above table shows a very intriguing aspect; a long demarcation between knowing about the subject librarians and actually knowing their respective subject librarians. Table Table 7 clearly shows that library users are not very interested with their respective subject librarians; $34.3 \%$ know there's while $52.9 \%$ are not aware. $12.8 \%$ are not interested in knowing, hence their indifference status.

- Have you asked for help from your subject librarian before?

\begin{tabular}{|c|c|c|c|}
\hline S/N & Items & Responses & Percentage \\
\hline A & Yes & 8 & 11.4 \\
\hline B & No & 45 & 64.3 \\
\hline C & Indifferent & 17 & 24.3 \\
\hline
\end{tabular}

Table 10

The above table shows a further degeneration of the supposed link or relationship with the respondent's respective subject librarians. Only $11.4 \%$ of the entire respondents have actually asked for help from their subject libraries, who is 
meant to be a center piece of their library usage. A large number of the respondents: $64.3 \%$ have not had any dealings with theirs. $24.3 \%$ are indifferent, showing that they don't actually care.

- What tools or platforms do you consider the best in accessing information outside the library?

\begin{tabular}{|c|c|c|c|}
\hline S/N & Items & Responses & Percentage \\
\hline A & Phones and internet & 46 & 65.7 \\
\hline B & Computer and internet & 19 & 27.1 \\
\hline C & Textbooks and computer & 2 & 2.9 \\
\hline E & Indifferent & 3 & 4.3 \\
\hline
\end{tabular}

Table 11

The above table shows that accessing information online/the internet is the highest medium for the respondent amidst others; it has $65.7 \%$ going for phones and internet, computer and internet has $27.1 \%$, $2.9 \%$ goes for those that prefer textbooks and computers while the indifferent respondents are $4.3 \%$. This gives us the idea of the place of technology and hardcopy books in information accessibility today. Put differently, it gives us the idea of the traditional library and the ICT driven libraries today.

In summary, given the above presentations, the research work sort to consolidate its findings using a tabular library monthly official statistic collated by the circulation unit. For the purpose of this work, the statistical data for the months of January through June 2019 was used.

\begin{tabular}{|c|c|c|c|c|c|}
\hline MONTH & RDRS & B.C & B.C \% & B.B & B.B \% \\
\hline January & 3,692 & 206 & $5.6 \%$ & 5 & $0.1 \%$ \\
\hline February & 12,526 & 12 & $0.1 \%$ & 50 & $0.4 \%$ \\
\hline March & 81,432 & 814 & $1.1 \%$ & 149 & $0.2 \%$ \\
\hline April & 35,631 & 798 & $2.2 \%$ & 63 & $0.2 \%$ \\
\hline May & 47,561 & 950 & $2.1 \%$ & 165 & $0.3 \%$ \\
\hline June & 70,801 & 1,755 & $2.5 \%$ & 334 & $0.5 \%$ \\
\hline
\end{tabular}

Table 12: University of Jos Bauchi Road Library Statistics: January- June 2019

Source: Circulation Unit, Bauchi Road Main Library, University of Jos, Nigeria. (2019)

KEY: RDRS: Readers

BC: Books Consulted

BB: Borrowed Books

$\%:$ Percentage

Table 12 glaringly shows that the views of the respondents in the above tables (1.0 to 2.0) presented are not far from the obtainable based on the statistical data from the University of Library. These figures show that while a lot of students enter the library, not all of them are ardent users of the library. The highest percentage of books consulted is seen in the month of January, which is just $5 \%$, the other months are between $0.1 \%$ and $2.5 \%$. For book borrowing, it is deeper in the negative outcome; no month recorded up to $1 \%$. This buttresses what we find in the respondent's view. The understanding that library users hardly borrow books goes a lot to tell about the place of the library on the users; if it is a place that has great influence in them and theyunderstand its flow, it cannot have a large number of patrons and yet have very few that consult and borrow books from it. There must be a way of rechanneling this misplaced priority on the part of the patrons.

\section{Recommendation}

\subsection{Proactive Feedback Mechanism}

Because the library is primarily based on user satisfaction, academic libraries should initiate a vibrant feedback mechanism that will enable them know the pressing needs of the users as frequent as possible and how to make them available. Doing this will keep the library relevant to its users. Pertinent on getting this right is hinged on a special team of tech-oriented librarians that will develop the needed platform for such to thrive.

From the preference of the respondents above, phones and the internet are preferred by the student in accessing needed resources or information. Developing an easy but robust means of connecting all the university students to serve their various needs like socializing, educating and enticing forms of information accessibility (where the library now comes in). Achieving this will go a long way to easily get the students to buy the idea if it is an App. The researchers advocate for what we call, 'Patrons App'. This App will help the students satisfy their social needs as can be designed or put in place according to the uniqueness of every institution, while solving the issues that concerns students library registration, access to the library resources both online and offline, borrowing of books, library information on new arrivals, adverts or information from the school, the Use of Library lectures and materials under General Studies (GST) etc. Using this means, ably managed by the aforementioned team above, to show consistency and update in the innovation, will definitely increase the relevance of the library since it is at their fingertips. 


\subsection{Staff Orientation and Development}

Library staff; Para professionals and professionals should be trained and developed on the trending forms of technology and how they can be used to improve the activities of the library so as to be in tune with the expected actions and reactions from the users. These orientation and development should be based on three aspects: Technical Know Why (reasons or justification for such training), Technical Know How (Proper learning of its practicality) and Technical Show How (being able to show oneself capable of the practical lessons learnt by carrying it out).

\section{Conclusion}

Going by the respondents view on the above discussed, it is clear that the academic library needs to reinvent itself to still remain relevant in the life of information and information seekers. Librarians (Para professionals and professionals), should always be in the fore front of desiring to acquire new knowledge, especially in relation to ICT, as this is the spur of the moment. The Library management should also play its part by creating the needed avenues for such to happen because one of the primary issues have been the ability for managements to accept change as they come, rigidity takes the center stage when it comes to exploring new avenues of making things work because of the fear of trending into some unknown destinations by especially the tech-savvy librarians that are open, ready and pushing for the needed change. Usually the fear is based on the fact that the management will no longer be relevant and the knowledge they have already been threatened to be obsolete or not very relevant. This should not be the case because the primary goal should be to give the needed efficient service to the users and any way that is seen to be the delight of the users should be the focus. Allowing such to take place makes the management succeed, irrespective of who is practically involved. By and large, the focus should be on embracing the user-oriented ideasto make the academic library user-friendly and or userrelevant.

\section{References}

i. Akintunde, S. (1999). The Migration: Digitization of the University of Jos Library. An Invited Paper presented at the 1999 Annual Seminar of the Committee of University Librarians of Nigerian Universities (CULNU) held at the University of Jos, Jos, April 21st, 1999.

ii. Apukea, O.D. and Iyendoc, T.O (2018). University students' usage of the internet resources for research and learning: forms of access and perceptions of utility. https://www.ncbi.nlm.nih.gov/pmc/articles/PMC6299120/. Accessed on the 10th/05/2019.

iii. Encyclopedia Britannica. The history of libraries: the ancient world. https://www.britannica.com/topic/library /Library-materials. Accessed on the 7th/05/2019.

iv. Matthews, S (2014). The 21st Century Library Paradigm Shift? 21st Century Libraries- Innovation, Information and High School Diplomas. https: 21stcenturylibrary.com. Accessed on the 10th/05/2019.

v. Staikos, K (2007). A History of the Library in Western Civilization (New Castle, DE: Oak Knoll Press, 2004- 12); Simon Eliot and Jonathan Rose, eds., A Companion to the History of the Book. Malden, MA: Blackwell.

vi. Williams, P. J (2014). Rebranding libraries. thelibraryelement.com/category/library-management. https://thelibraryelement.com/2015/12/17/student-agency-a-paradigm-shift-in-the-role-of-the-library-inlearning/. Accessed on the 10th/05/2019. 